\title{
Did My Brain Implant Make Me Do It? Questions Raised by DBS Regarding Psychological Continuity, Responsibility for Action and Mental Competence
}

\author{
Laura Klaming • Pim Haselager
}

Received: 29 April 2010 / Accepted: 7 September 2010/Published online: 16 September 2010

(C) The Author(s) 2010. This article is published with open access at Springerlink.com

\begin{abstract}
Deep brain stimulation (DBS) is a wellaccepted treatment for movement disorders and is currently explored as a treatment option for various neurological and psychiatric disorders. Several case studies suggest that DBS may, in some patients, influence mental states critical to personality to such an extent that it affects an individual's personal identity, i.e. the experience of psychological continuity, of persisting through time as the same person. Without questioning the usefulness of DBS as a treatment option for various serious and treatment refractory conditions, the potential of disruptions of psychological continuity raises a number of ethical and legal questions. An important question is that of legal responsibility if DBS induced changes in a patient's personality result in damage caused by undesirable or even deviant behavior. Disruptions in psychological continuity can in some cases also have an effect on an individual's mental competence. This capacity is necessary in order to obtain informed consent to start, continue or stop
\end{abstract}

L. Klaming $(\bowtie)$

Tilburg Institute for Law, Technology, and Society, Tilburg University,

P. O. Box 90153, 5000 LE Tilburg, The Netherlands

e-mail: 1.klaming@uvt.nl

\section{P. Haselager}

Donders Institute for Brain, Cognition and Behaviour,

Radboud University Nijmegen,

Montessorilaan 3,

6525 HR Nijmegen, The Netherlands

e-mail: w.haselager@donders.ru.nl treatment, and it is therefore not only important from an ethical point of view but also has legal consequences. Taking the existing literature and the Dutch legal system as a starting point, the present paper discusses the implications of DBS induced disruptions in psychological continuity for a patient's responsibility for action and competence of decision and raises a number of questions that need further research.

Keywords Deep brain stimulation · Personal identity . Psychological continuity · Responsibility for action .

Mental competence

\section{Introduction}

Deep brain stimulation (DBS) is a well-accepted treatment for movement disorders, including Parkinson's disease (PD), Dystonia and Essential Tremor if symptoms are medically intractable and/or medical treatment has serious side effects. The application of DBS in patients with movement disorders was found to result in considerable alleviation of motor symptoms and reduced medication needs [1-5]. The finding that DBS affects neural activity in brain areas involved in cognitive and affective functions led to the extended use of DBS from motor disorders to psychiatric disorders including depression $[6,7]$ and obsessive-compulsive disorder [8-10]. Given the successfulness of the treatment and the continuing advancement of the technology, it seems likely that 
DBS will be expanded to other psychiatric populations. The finding that DBS has several positive effects, for instance memory enhancement [11], alleviation of alcohol dependency [12] and reduction of aggressive behavior [13], gave furthermore reason to the assumption that DBS may be effective in treating other conditions, such as Alzheimer's disease and drug addiction. Moreover, it has been suggested that DBS might be applicable within criminal justice in order to treat offenders and eventually decrease criminal behavior [14]. While especially the latter idea is rather speculative at this point in time, DBS is actually being explored as a treatment option for various disorders including Alzheimer's disease, depression, anxiety disorders, and Tourette's syndrome $[6-10,15,16]$. DBS is therefore currently used in both therapeutic settings, i.e. as treatment for movement disorders, and in experimental settings, i.e. to test its effectiveness as treatment for various neurological and psychiatric disorders.

Although DBS has important therapeutic effects for otherwise treatment resistant conditions, there is potential for serious complications, such as haemorrhage and infections, and unexpected side effects, including cognitive and psychiatric symptoms. The most common cognitive and psychiatric problems that have been reported concern a decline in word fluency and verbal memory [1, 17-19], depression [5, 20], increased suicide tendency [20-22], anxiety [2], emotional hyperreactivity [2] and hypomania [2, 23, 24]. Some of these side effects might also affect aspects of the patient's personality, i.e. his unique character traits, as reflected by his thoughts, desires, motivations and behavior (for a more detailed discussion on personality see e.g. [25-27]). So far, little is known about the impact of DBS on patients' personality. Nevertheless, DBS induced changes in personality have been observed in some cases [15, 24], while others have found no or little impact on personality [2, 8, 28]. Alterations in mental states critical to personality could affect an individual's personal identity, i.e. the experience of psychological continuity, of persisting through time as the same person [29]. Since there are various possible cognitive and psychiatric side effects, and effects of DBS on personality have been observed, it can be hypothesized that disruptions in psychological continuity can occur in patients undergoing DBS. So far however, there has been no systematic empirical research on the effect of DBS on an individual's psychological continuity and hence little is known about the influence of DBS on an individual's identity. The possibility of DBS induced changes in an individual's personality and identity entails important ethical and legal questions, for instance regarding responsibility for action and mental competence.

Before discussing this topic in more detail, two issues need to be mentioned. Firstly, the probability for side effects to occur depends in part on the exact site of stimulation [30]. In PD for instance, adverse events (affecting the patients' cognitive, psychiatric and behavioral status) at 4-years postsurgery were found to be higher in subthalamic nucleus stimulation compared to stimulation of the globus pallidus internus and the ventral intermediate part of the thalamus [31]. Although we will be discussing the issue of DBS and psychological continuity in general, it is important to realize that DBS induced changes in an individual's personality and the consequences thereof depend on the specific application of DBS. The second issue concerns the difference between experimental and therapeutic use of DBS. In experimental settings, the possibility of adverse reactions may be high. This is typically taken into account, because the exact likelihood and extent of possible side effects is unknown, or may even constitute one of the explicit research targets of the study (see, e.g. 32). In contrast, if DBS is used in therapeutic settings, patients may expect that the risk of serious adverse effects, such as personality changes, is small. Although we will discuss the implications of DBS induced personality changes in general, these implications seem to be particularly pressing within therapeutic settings.

The potential of unwanted side effects - that may or may not affect psychological continuity and personal identity - does of course not diminish the avail of DBS as a treatment option for various serious and treatment refractory conditions. Instead, discussing these adverse effects might contribute to realize the full potential of DBS, for instance by emphasizing the importance of excluding individuals with certain preconditions or comorbidities from the pool of qualified candidates for the treatment. In addition, it allows for an exploration of the ethical and legal implications of DBS induced disruptions of psychological continuity. In this paper, we will explore how DBS induced alterations in the personal identity of the 
treated individual may affect his responsibility for actions and decisions. It bears emphasis that it is not our aim to argue that DBS will always, or even often, lead to serious changes in personal identity. We will suggest that DBS might (conceivably and at times in practice) affect psychological processes to such an extent that effects on personal identity cannot be excluded. The aim of this paper is to explore the consequences of DBS induced disruptions in psychological continuity for an individual's responsibility for action and competence of decision, taking into account the difference between established therapeutic and experimental settings. We take some of the case studies described in the literature and the Dutch legal system as a starting point to illustrate some of the most urgent questions raised by DBS induced changes in the personal identity of the treated individual.

\section{Personal Identity, Responsibility for Action and Mental Competence}

The topic of personal identity is a rather complicated one, and we cannot possibly do justice to its full history and its many nuances in this paper. Instead, we will focus on two practical issues that arise when examining the impact of DBS on personal identity. Specifically, these issues concern responsibility for action and mental competence. From a legal perspective, it is essential to address the question whether a patient who received DBS and experienced a change in his personal identity as a result of the treatment can be held responsible for his actions. If a DBS patient causes some kind of damage that he might not have caused if he had not received the treatment, it is not intuitively clear that he is to be held (completely) responsible for his actions. We will also discuss the effect that alterations in an individual's personal identity might have on his mental competence, i.e. the ability to remember, understand and decide upon relevant information [32]. This capacity is necessary in order to obtain informed consent to start, continue or stop treatment, and it is therefore not only important from an ethical point of view but also has legal consequences.

The problem of personal identity over time has been the subject of substantial philosophical debates [e.g. 33-46]. Although several different theories exist, we will focus here on what has been called the standard view', i.e. those theories that find their basis in psychological criteria of personal identity (PCPI). This set of theories belongs to the oldest (Locke) and still most influential [e.g. 37-39, 42-44, 46, see 33, $34,36,40,41,46]$ for criticisms and alternatives] within philosophy and fits well with the legal emphasis, as we will see below, on psychological properties (e.g. rationality) of human beings.

John Locke is generally considered as the founding father of PCPI. He advocated a psychological continuity criterion based on memory. Relevant to this paper is Locke's emphasis on the forensic, normative implications of his analysis of a person. About the concept of 'person' Locke (1694, II, xvii, 26) said: “It is a forensic term, appropriating actions and their merit; and so belongs only to intelligent agents, capable of a law, and happiness, and misery. This personality extends itself beyond present existence to what is past, only by consciousness,- - whereby it becomes concerned and accountable; owns and imputes to itself past actions, just upon the same ground and for the same reason as it does the present."

More formally, though still in a somewhat simplified form, the PCPI holds that a person $\mathrm{X}$ at $\mathrm{t} 1$ is the same person as $\mathrm{Y}$ at $\mathrm{t} 2$, if $\mathrm{X}$ is (uniquely) psychologically continuous with Y. The psychological continuity consists of overlapping chains of direct psychological connections like memories, intentions, beliefs, goals, desires, and similarity of character [38, 44]. It bears emphasis that the focus on the continuity of psychological functions and properties allows for an operationalization by means of standard psychological tests such as Tellegen's Multidimensional Personality Questionnaire (MPQ) [47], the Iowa Personality Questionnaire (IPQ) [48], and tests for cognitive and executive functioning (see e.g. the large test set used by Witt et al. [49]).

Many philosophical debates have raged and continue to do so about the relative importance of the concepts used in order to state the continuity, whether it is better to speak of 'connectedness' instead of 'continuity' and on the issue of whether or not this continuity should be unique (i.e. effectively singling out one and only one person). Although for this reason it is good to keep in mind that we are speaking about a set or family of theories, we will take the PCPI principle in its above, general formulation, as the starting point for our analysis of the ethical and legal questions raised by DBS with regard to responsibility for actions and decisions. 
The central question thus becomes whether the use of DBS does, or could under certain circumstances, affect the psychological continuity standardly taken to be characteristic of personal identity. That this is not idle speculation becomes clear from a recent presentation of a case illustrating that DBS can cause changes in identity as defined by the PCPI principle. A 43-yearold man suffering from Tourette's Syndrome received DBS, because the symptoms had a major impact on his life and drug treatment was unsuccessful and had evoked major side effects [15]. The target sites and the stimulation procedure were considered both safe and efficacious for the (partial) relief of his tics [15]. The DBS treatment was successful and the patient learned to adjust the stimulation parameters himself so he could better control his tics. However, 12 months after the operation, the patient had developed a dissociative response, i.e. an alternate identity state, when the amplitude of the stimulation was increased. This gave the physicians the opportunity to use this case in an experimental setting to explore the neurological basis of dissociation. Increasing the amplitude of stimulation resulted in the patient "anxiously crouching in a corner, covering his face with his hands. He spoke with a childish high-pitched voice and repeatedly insisted that he was not to blame. Sentences were brief and grammatically incorrect. If approached by one of us, he fiercely kicked his feet because he feared being thrown in the basement." [15, p. 545]. When the amplitude of the stimulation was decreased, the patient's responses became adequate again and he was unable to recall what exactly had happened, although he could report to have been overwhelmed by bad childhood memories [15]. This case demonstrates that DBS can impinge on psychological continuity (in this case by having profound effects on behavior and memory) and influence an individual's personal identity to such an extent that an alternate personality state can be observed.

This case suggests that DBS induced disruptions in psychological continuity can occur relatively quickly, since the patient's behavior changed immediately after the stimulation was increased and disappeared immediately after the stimulation was decreased. It is not entirely clear however whether the dissociative response was the result of an increase of the amplitude of the stimulation and thus would also have occurred if stimulation had been increased immediately after the surgery, or whether the disso- ciative response occurred gradually and emerged 12 months after the implantation of the electrodes. In general, sudden changes may be rare (though they do occur, see e.g. 50). Rather, changes in an individual's personality may occur gradually over a considerable period of time after the stimulation has been turned on $[23,51]$. This issue clearly requires more systematic empirical research. The timescale involved in DBS induced personality changes is important for two reasons. Firstly, the effects of DBS over longer periods of time might be less easily reversible, due to adaptations within the brain to prolonged stimulation. ${ }^{1}$ If it turns out to be true that DBS is not as reversible as commonly assumed, this could significantly increase the ethical concerns about DBS induced personality changes discussed in this paper. Secondly, the effects of DBS over longer timescales might be difficult to assess independently of the continuing changes (e.g. progressive neuronal degeneration) taking place within the patient, as DBS is a non-curative therapy. This may make an assessment of the ethical implications of DBS less straightforward. These issues concerning the timescales involved in DBS induced changes in an individual's personality are in need of further investigation. For the purpose of our paper, the primary concern are the consequences of DBS induced personality alterations rather than the timescales along which DBS might affect personality.

Since the above cited case demonstrates the possibility of DBS induced disruptions in psychological continuity - regardless of whether these occur immediately or several months after the treatment - it seems necessary to not only empirically explore the factors involved in these disruptions, but also to address the ethical and legal implications thereof. In the following sections, we will illustrate the effects that DBS induced disruptions in psychological continuity may have for an individual's responsibility for action and mental competence in more detail and raise questions that need further research.

\section{Psychological Continuity and Responsibility for Action}

According to Morse, the legal concepts of personhood and responsibility are practically oriented [52]. Per-

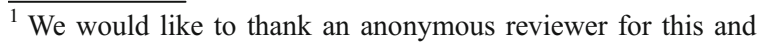
several other insightful suggestions.
} 
sons are treated as potentially rational intentional agents, whose actions are governed by reason. Law is a system of rules that is meant to guide or influence behavior, by providing a person with reasons for forbearance or action, as premises in practical syllogisms. Law can only guide action if human beings are rational creatures, capable of understanding and conforming to legal requirements through intentional action. Hence, it is assumed that human beings are capable of at least a minimal form of rationality. Morse indicates that the emphasis on rationality is so strong that "some people who commit crimes under the influence of mental disorder are excused from responsibility because their rationality was compromised, not because mental disorder played a causal role in explaining the conduct" [52, p. 38]. According to the Dutch Criminal Code, an individual cannot be held responsible if he acted irrationally at the time he committed a crime: "Not punishable is he who commits a criminal act for which he cannot be held responsible because of a defect of disorder of his mental capacities" [53].

It is not improbable that DBS may in some cases produce psychological changes leading to behavior that is morally and legally questionable. Several cases in which DBS has led to increased impulsivity and aggressiveness [2, 50, 54], or inappropriate sexual behavior [2], both of which could result in wrongful or even criminal behavior, have been reported in the literature. It is therefore questionable whether a patient who received DBS should be held (completely) responsible for his actions. It is currently unclear how to deal with questions of responsibility if DBS changes a patient's cognitive or emotional states and these changes cause undesirable or even deviant behavior.

We suggest that at this point much (though not everything) can be learned from discussions concerning responsibility for action in two distinct fields. Firstly, an analogy to patients whose behavior may have been influenced by medication can be drawn. Most medications, especially those used to treat serious disorders, have the potential for adverse reactions. For instance, Levodopa, which is frequently prescribed to PD patients, may cause "hedonistic homeostatic dysregulation syndrome" resulting for instance in inadequate impulse control [57], which may in turn make the patient behave in a way that causes damage. The overlap between DBS and medication with regard to their potential for undesir- able adverse reactions allows for a comparison of the two conditions with regard to responsibility for action. Secondly, an analogy can be drawn to patients with Dissociative Identity Disorder (DID, also known as Multiple Personality Disorder ${ }^{2}$ ). DID is a psychiatric disorder that is characterized by "the presence of two or more distinct identities or personality states" [58, p. 487]. These alters recurrently take control over the person's behavior with an associated memory loss that goes beyond normal forgetfulness [58]. Although the identity changes in DID are more dramatic and appear to be more constant than personality changes that might be caused by DBS, the fact that both involve psychological discontinuities allows for a comparison of the two conditions concerning questions of responsibility for action.

\section{Responsibility for Action in Patients under the Influence of Medication}

Most medical treatments or interventions can have unwanted side effects, some of which may even lead to morally or legally questionable behavior. For instance, it is well known that antidepressants can have effects such as mania, agitation and akathisia, which is an inner agitation that typically manifests itself in the inability to stop moving and that has been associated with increased aggressiveness [59-63]. These behavioral reactions can result in violence and other forms of abnormal behavior, including abnormal sexual behavior in some patients, especially in the initial period of taking the medication [62]. In a case described by Dorevitch et al., [62], a patient developed mania after taking fluvoxamine, a selective serotonin reuptake inhibitor, resulting in inappropriate behavior with sexual advances towards other patients. Furthermore, there are several cases in which indi-

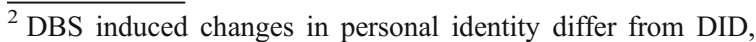
mainly because the latter seems to be the most extreme form of identity alterations and in DID, distinct identities exist in one body at the same time. Additionally, DBS induced personality changes are generally considered to be reversible, i.e. by turning off the stimulation or changing its parameters, and therefore more easily controllable. However, as noted above, the effects of prolonged DBS use are still not very well known, and that it is conceivable that this might lead to sustained changes of personality and behavior, even after terminating DBS. Also, we are aware of the controversy around DID [e.g. $55,56]$, but this debate is beyond the scope of this paper.
} 
viduals without any prior history of aggressive or violent behavior suddenly behaved violently after taking antidepressants [59-61, 63, 64]. Several legal cases linking violent behavior to the use of antidepressants have been reported [59-61]. For instance, in 1998, a 65-year old man without any history of violence or other serious disturbances was prescribed an antidepressant by his general practitioner in order to treat his anxiety and depressive episodes. Only 2 days after he had started taking the medication, he murdered his wife, daughter and granddaughter before killing himself. The pharmaceutical company that marketed the antidepressant was sued by the sonin-law and deemed $80 \%$ responsible for the events since according to an expert witness the antidepressant probably caused akathisia or psychosis which led to the homicidal behavior [60].

Under the law, an individual can under certain circumstances be declared not (fully) accountable for his actions if he was intoxicated at the time of the incident. It is important to note that there is a difference between voluntary and involuntary intoxication; an individual is typically held criminally responsible for behavior committed under the influence of alcohol or illegal drugs, because it is presumed that he knew that the substance could impair his ability to control his impulses and his ability to make rational judgments. Hence, someone who acted criminally or negligently while under the influence of alcohol or illegal drugs is considered to have acted intentionally and is held responsible for his actions. Involuntary intoxication in contrast, which can be caused by taking a prescription drug, can lead to the verdict that an individual cannot be blamed for his actions and is therefore not (fully) responsible [65]. Hence, involuntary intoxication can be a mitigating or exonerating factor in court, because the suspect could not foresee the consequences of taking the medication [65]. Although rather rare in the Netherlands, these cases exist in legal practice. For instance, in a decision of the court in Arnhem, the offender - a man who had killed his wife by parking their car on a railroad crossing — was judged to have acted without intention because of a combination of stress, sleep deprivation and the use of medication prescribed for sleeplessness, leading to his acquittal from murder charges [66]. In another case, a 64-year old woman who had taken antidepressants and murdered her husband and daughter before trying to commit suicide was considered to have diminished responsibility for her actions. The expert testimonies concerning the impact of her depression and the medication on her behavior were inconsistent, ranging from slightly diminished responsibility to complete absence of responsibility. ${ }^{3}$ She was ultimately convicted for murder, but received a reduced sentence due to her diminished responsibility [67].

Since there are several similarities between DBS and medication, considering how the legal system deals with questions of responsibility for action if the suspect's personality and subsequent behavior were influenced by involuntary intoxication can inform how cases in which DBS induced personality changes which may lead to violent behavior could be handled. Both DBS and medication are intended to benefit the individual. In both cases, deciding to cease treatment because of unwanted side effects is difficult when there is no alternative treatment. Nevertheless, disruptions in psychological continuity and resulting aggressive or impulsive behavior seem to warrant termination of treatment. With regard to responsibility for action, the question arises whether disruptions in psychological continuity caused by DBS are similar to personality changes caused by medication and should therefore be considered involuntary intoxication.

\section{Responsibility for Action in DID Patients}

As Kennett and Matthews [68, p. 509-510; see also 72] formulate the problem succinctly: "if someone with DID acts in a morally or legally bad way, can we hold this individual responsible when it is claimed that the accused personality is not the personality who acted?" Regarding DID, it is of course possible to claim that we are dealing either with one single person having two alters, or with two different persons. We suggest that the proper way, given the pragmatic legal concerns, to deal with this question is to invoke the PCPI. That is, if significant discontinuities with respect to memories, intentions, beliefs, goals, desires, and similarity of character are sufficient to be considered as leading to a differentiation

\footnotetext{
${ }^{3}$ A 5-point scale for responsibility (complete responsibility slightly diminished responsibility - diminished responsibility severely diminished responsibility - complete absence of responsibility) is used in forensic practice in the Netherlands.
} 
between the (degrees of) rationality of the two alters, then at least a serious consideration of the possibility that we are dealing with two different persons is warranted. Several researchers have argued that the claim of DID patients that they are not responsible for the actions of one of their alters should seriously be considered [68-72].

A classic case mentioned by Kennett and Matthews [68, p. 510] can be instructive here. It is the case of Eve: Eve White was quite, demure, retiring, and industrious. Her alter, Eve Black, was shrewd, rowdy, and provocative. While White was unaware of Black, Black knew about White and liked to cause her discomfort ("When I go out and get drunk" (..) Eve Black once said (..) "She wakes up with the hangover. She wonders what in the hell's made her so sick."). It is clear that in this case there is some form of psychological discontinuity regarding memory (though apparently only one way $^{4}$ ), that is directly related to the topic of responsibility and punishment (albeit in a non-legal way). Moreover, one may have good grounds to argue that, as Kennett and Matthews [68, p. 511] formulate it, "the patient does not possess the relevant capacities of judgment and control" with respect to the actions committed in an alter state. Hence, the discontinuity arguably is affecting the rationality attribution to Eve White regarding the actions of Eve Black.

Interestingly, judicial decisions in which the suspect is acquitted of murder or manslaughter because of a mental disorder are often (at least in the Netherlands) based on a diagnosis of dissociative disorder [73]. In order to provide some insight into judicial decisions concerning the relation between intent and mental disorder, Stevens and Prinsen [73] analyzed manslaughter cases in the Netherlands in which the presiding judge decided that the suspect lacked intention because of a mental disorder [73]. This analysis revealed that in these cases, the suspect was typically considered to have suffered from dissociation at the time he committed the crime. To

\footnotetext{
${ }^{4}$ There is a distinction between knowing or remembering that I drank or had a headache and knowing or remembering the drinking or having the headache. From the description, it appears that Eve Black has (access to) both regarding the drinking and the first, declarative, but not the second, episodic type of memory regarding the headache. Eve White appears to have (access to) neither the declarative nor the episodic knowledge or memory of the drinking, but does have both for the headache.
}

give an example, a suspect who was accused of having strangled his wife was diagnosed with an acute dissociative disorder during the time of the crime, i.e. his consciousness, memory, identity and perception were disintegrated and he therefore lacked cognitive control over his actions. This diagnosis was accepted by the presiding judge as evidence for a lack of intention on the basis of which the suspect was acquitted and left the courtroom as a free man [73, 74]. Apparently, individuals who act in a state that is dissociated from their real identity are often not held criminally responsible for their actions.

It is possible to disagree with what would count as a proper interpretation of cases in which an individual with DID acts in a morally or legally irresponsible way. In fact, Kennett and Matthews' paper is a reply to Sinnott-Armstrong and Behnke [72] who hold that, at least in some cases, a person can be held morally and legally responsible for actions committed by an alter as long as the alter can be considered to possess the capacity to appreciate the wrongfulness of a particular conduct or conform his conduct to the requirements of the law [72].

The issue here is not whether we agree with one of the viewpoints only briefly discussed above. Rather, the question that we raise here is whether there is reason to believe that DBS can lead to legally relevant discontinuity type of phenomena regarding memories, intentions, beliefs, goals, desires, and similarity of character between the patient in 'DBS-on' and 'DBSoff' conditions. Moreover, could these discontinuities be so severe that similar (not necessarily exactly the same) kinds of debates about personal responsibility as in the case of DID are justified? If someone who has received DBS acts in a morally or legally bad way, can we hold this individual responsible when it is claimed that the person who acted is not the same person as before the treatment? Current review papers $[75,76]$ indicate that the jury is still out on the effects of DBS on personal identity. Several case studies however suggest that DBS can induce rather large changes in psychological continuity $[15,51]$. An illustrative case in this regard is that of a 65 -year-old woman who received DBS in order to treat her PD and who experienced "a remarkable mood change" [51, p. 1383]. The patient became euphoric and started to talk excessively. As the physicians report, "she lost normal social inhibitions, was in love with two neurologists, and tried to embrace and kiss people. She 
was hyperactive and restless, she left the clinic several times without permission and engaged in unrestrained buying of clothing." [51, p. 1383]. In addition, she developed psychotic symptoms, suspecting her sons of conspiring against her, and became hostile. Although the patient in this case did not develop an alternate identity, the changes in her personality, i.e. mania and psychotic symptoms, are so severe that one may speak of disruptions in psychological continuity. It is difficult to determine responsibility for action if these disruptions in psychological continuity lead to wrongful or even criminal behavior. Based on the literature on the responsibility of DID patients, it can be argued that if normally integrated functions of memory, intentions, beliefs, goals, desires, and similarity of character of a patient are disrupted as a result of the DBS treatment, it is not intuitively clear that he should be held (completely) responsible for his actions.

\section{Psychological Continuity and Mental Competence}

If DBS affects psychological continuity, then this might influence a person's mental competence, i.e. the ability to remember and understand relevant information and to make a decision on the basis of this information [32]. In turn, this might affect, or even lead to the loss of the ability to make reasonable decisions about the continuation of the treatment. Hence, although DBS can extend a patient's freedom considerably_enabling him to live a life independent from constant care - it may at the same time affect the patient's decisional capacity and hence his autonomy. In cases in which DBS has a substantial effect on psychological continuity, it may be necessary to determine whether the patient can make a decision about the continuation of his treatment or whether the decision should be made by a legal representative and the medical team.

As pointed out by Glannon [77], the loss of decisional capacity in cases in which DBS has caused substantial personality alterations can be viewed as different in several ways from the typical case of advance directives in which a patient has to make a decision about the continuation of treatment at a later stage of the illness when he may no longer be competent to make well-informed decisions. In contrast to many other disorders, for instance Alzheimer's disease, the loss of decisional capacity in DBS patients may not be gradual, but can occur rapidly, or even immediately after turning stimulation on. An additional difference between DBS and most other disorders concerns the reversibility of the condition. Although complete reversibility may be questionable, at least in some cases, if DBS is turned off, mental competence can be regained.

The problem of mental competence in patients who receive DBS and experience disruptions in psychological continuity is even more complex, since granting the patient his autonomy with regard to the decision about the continuation of treatment, raises a new question; if the patient makes an autonomous decision, in which state should he make it, when stimulation is turned on or when it is turned off? This problem is best illustrated by a case study discussed by Leentjens and colleagues [23]. A 62-year-old PD patient developed a manic disorder after receiving DBS. The stimulation had caused serious personality changes including chaotic behavior, megalomania and mental incompetence. In this state, the patient did not suffer from motor impairments, but due to his impaired psychiatric functioning he was considered unable to live on his own. When DBS was turned off, his insight and capacity to judge returned. Since the psychiatric symptoms could not be treated medically, and without DBS the patient's motor symptoms exacerbated, it was decided to either disable DBS and admit the patient to a nursing home because of severe motor impairment, or to continue DBS and admit him to a psychiatric institution because of severe mental impairment [23].

This decision however entailed three important problems. Firstly, the medical team needed to determine in which state the patient should be asked about whether or not to continue the treatment; either when stimulation was on and mental capacity was impaired, or when stimulation was turned off and mental capacity was unimpaired. Following the advice of the hospital's ethical commission, it was eventually decided to ask the patient when stimulation was turned off, so that he could decide in a mentally competent state [23; see also 78], and he decided that he wanted to continue with DBS and consequently be admitted to a psychiatric institution.

The second problem concerned the implementation of this decision [23]. According to Dutch health law, judicial authorization in a psychiatric hospital is only possible if the harm cannot be averted by interference of a person or institution [79, article 2]. Additionally, a treatment plan focusing on removing the harm that is responsible for the patient's hospitalization is 
required by law [79, article 38]. The harm, i.e. the patient's altered personality and the behavior resulting from this alteration, could have been averted or removed by turning off the DBS. Hence, none of these legal requirements was fulfilled. This ascertainment suggests that current regulation does not sufficiently cover issues that are raised by treatment with new technologies such as DBS.

The third problem brings us back to the initial problem. Since DBS already influenced the patient's personality considerably (at least when stimulation was turned on), it is possible that continuation of the treatment will ultimately result in permanent and potentially even irreversible changes in the patient's personality. The difficulty arising from this is whether and to what degree the patient can be considered to be able to foresee the possible consequences of the treatment and the effect this has on his identity. Moreover, this raises the question whether the treating physicians or a legal representative should interfere in the decision or be able to cancel the treatment at a later point in time in order to protect the patient from any (further) changes to his identity, which could undermine the patient's autonomy [23]. As this case shows, DBS can in some cases interfere with the patient's mental competence, which can render the patient unable to make a reasonable decision about the continuation of the treatment. It is therefore important to not only develop guidelines that will help treating physicians to make decisions in these cases, but moreover to adjust current legal rules to capture issues raised by new technologies such as DBS.

\section{Conclusion and Questions for Further Research}

The increasing use of DBS will lead to a vigorous debate about the personality and personal identity of patients receiving DBS, especially in relation to assessments of their responsibility for action and capacity to make decisions. As described above, the application of DBS is currently accompanied by a lack of clarity concerning questions of responsibility for action and mental competence. By comparing personality changes induced by DBS to personality changes induced by medication, as well as by comparing disruptions in psychological continuity in DBS patients to disruptions in psychological continuity in DID patients, we attempt to stimulate the discussion of responsibility for action in DBS patients. Both medication and DID are similar to the effects of DBS in some regards and this suggests that questions about legal responsibility could be solved in similar ways. An analysis would certainly benefit from thorough legal research on this matter.

It is important to note that the question of responsibility is broader than described here. For instance, termination of treatment, e.g. induced by battery failure, might also cause undesirable-although probably not criminal-behavior. Battery failure could cause the patient to relapse into a state quite similar to the one before treatment which may result in damage. In addition, it can lead to undesirable behavior in individuals who were depressive before DBS treatment and suffered from suicidal thoughts. These issues raise questions concerning civil liability, e.g. the liability of physicians or manufacturers of DBS apparatus in relation to information duties regarding the patient. Both treatment and termination of treatment raise questions concerning criminal responsibility and civil liability. While we have limited ourselves to discussing responsibility for action in a criminal law context, there is an urgent need to deal with both questions concerning criminal responsibility and civil liability in cases in which either DBS treatment or termination of DBS treatment results in undesirable behavior and damage.

A similar conclusion can be drawn with regard to mental competence. There is currently a lack of clarity concerning certain health law aspects. Specifically, it is unclear how to deal with patients who, due to DBS, experience an alteration in their personality to such a degree that it affects their ability to make reasonable decisions about the continuation of treatment. For treating physicians it is necessary to know how to deal with these patients. Furthermore, it seems obvious that there is a need for adaption of current legal rules in order to account for patients with DBS (and other neurotechnological interventions). As described above, current regulation-at least in the Netherlands and presumably in most countries - is insufficient when dealing with DBS patients who are due to the treatment no longer capable of at least minimally rational decision-making. So far, none of the legal questions raised by DBS have received sufficient debate.

On a more general level, it will be necessary to address questions concerning the effect of DBS on patients' personality; not only whether these changes 
are harmful but more importantly, under what circumstances they might be harmful or undesirable. Personality changes may, at least in some cases, be the intended outcome in psychiatric patients rather than an unwanted side effect. Consequently, the question should be how much change in an individual's personal identity is acceptable and under what circumstances this is acceptable. Additionally, the consequences of these changes as well as their ethical and legal implications need further discussion. It bears emphasis that these issues can and will be addressed by different parties, viz. by (1) the patient him/herself, (2) significant others, (3) the involved scientific and clinical teams, and (4) society at large (e.g. law and public opinion). It is not to be expected that all four parties will agree on similar answers to all questions, even regarding the same case.

Moreover, the questions themselves are complex and diverse, and at this stage still in need of being formulated properly. Some of the most significant questions include, but are definitely not confined to, the following: How well do traditional concepts about personality and identity apply to patients receiving DBS who have undergone significant, at times quite rapid, and not always entirely foreseeable changes? Does the treatment amount to, or could it be conceptualized as, the person (temporarily) being cured, restored, complemented or changed? What influence does the possibility of a relatively quick reversal of these changes (through switching DBS off) play regarding the (un)acceptability of a particular interpretation? How reversible are personality changes induced by DBS? Could there be systematic differences regarding this conceptualization between the different people involved, i.e. the patient, the medical team, significant others, the family, friends, colleagues, neighbors? How do these changes and the way they can be conceptualized affect the person's (re-)adjustment to society, e.g. influence the roles they play within the contexts of relations, family, profession and society at large? What effect does the dependency on technology have on personal identity?

Considering that with advancements in the technology and due to its successfulness DBS will most likely be expanded to various clinical populations, questions concerning the effect of DBS on an individual's personality and personal identity as well as the ethical and legal consequences thereof need much closer attention. Research addressing these questions would not just benefit from but requires a multidisciplinary approach.

Open Access This article is distributed under the terms of the Creative Commons Attribution Noncommercial License which permits any noncommercial use, distribution, and reproduction in any medium, provided the original author(s) and source are credited.

\section{References}

1. Daniele, A., A. Albanese, M.F. Contarino, P. Zinzi, A. Barbier, F. Gasparini, L.M.A. Romito, A.R. Bentivoglio, and M. Scerrati. 2003. Cognitive and behavioural effects of chronic stimulation of the subthalamic nucleus in patients with Parkinson's disease. Journal of Neurology, Neurosurgery and Psychiatry 74: 175-182.

2. Houeto, J.L., V. Mesnage, L. Mallet, B. Pillon, M. Gargiulo, S. Tezenas du Moncel, A.M. Bonnet, B. Pidoux, D. Dormont, P. Cornu, and Y. Agid. 2002. Behavioural disorders, Parkinson's disease and subthalamic stimulation. Journal of Neurology, Neurosurgery and Psychiatry 72: 701-707.

3. Jahanshahi, M., C.M.A. Ardouin, R.G. Brown, J.C. Rothwell, J. Obeso, A. Albanese, M.C. Rodriguez-Oroz, E. Moro, A.L. Benabid, P. Pollak, and P. Limousin-Dowsey. 2000. The impact of deep brain stimulation on executive function in Parkinson's disease. Brain 123: 1142-1154.

4. Limousin, P., P. Krack, P. Pollak, A. Benazzouz, C. Ardouin, D. Hoffmann, and A.-L. Benabid. 1998. Electrical stimulation of the subthalamic nucleus in advanced Parkinson's disease. The New England Journal of Medicine 339(16): 1105-1111.

5. Weaver, F.W., K. Follett, M. Stern, K. Hur, C. Harris, W.J. Marks Jr., J. Rothlind, O. Sagher, D. Reda, C.S. Moy, R. Pahwa, K. Burchiel, P. Hogarth, E.C. Lai, J.E. Duda, K. Holloway, A. Samii, S. Horn, J. Bronstein, G. Stoner, J. Heemskerk, and G.D. Huang. 2009. Bilateral deep brain stimulation vs best medical therapy for patients with advanced Parkinson disease: A randomized controlled trial. Journal of the American Medical Association 301(1): 63-73.

6. Mayberg, H.S., A.M. Lozano, V. Voon, H.E. McNeely, D. Seminowicz, C. Hamani, J.M. Schwalb, and S.H. Kennedy. 2005. Deep brain stimulation for treatment-resistant depression. Neuron 45(5): 651-660.

7. Lozano, A.M., H.S. Mayberg, P. Giacobbe, C. Hamani, R.C. Craddock, and S.H. Kennedy. 2008. Subcallosal cingulate gyrus deep brain stimulation for treatmentresistant depression. Biological Psychiatry 64(6): 461467.

8. Gabriëls, L., P. Cosyns, B. Nuttin, H. Demeulemeester, and J. Gybels. 2003. Deep brain stimulation for treatmentrefractory obsessive-compulsive disorder: Psychopathological and neuropsychological outcome in three cases. Acta Psychiatrica Scandinavica 107(4): 275-282.

9. Greenberg, B.D., D.A. Malone, G.M. Friehs, A.R. Rezai, C.S. Kubu, P.F. Malloy, S.P. Salloway, M.S. Okun, W.K. Goodman, 
and S.A. Rasmussen. 2006. Three-year outcomes in deep brain stimulation for highly resistant obsessive-compulsive disorder. Neuropsychopharmacology 31: 2384-2393.

10. Sturm, V., D. Lenartz, A. Koulousakis, H. Treuer, K. Herholz, J.C. Klein, and J. Klosterkötter. 2003. The nucleus accumbens: A target for deep brain stimulation in obsessive-compulsive- and anxiety-disorders. Journal of Chemical Neuroanatomy 26(4): 293-299.

11. Hamani, C., M.P. McAndrews, M. Cohn, M. Oh, D. Zumsteg, C.M. Shapiro, R.A. Wennberg, and A.M. Lozano. 2008. Memory enhancement induced by hypothalamic/ fornix deep brain stimulation. Annals of Neurology 63(1): $119-123$.

12. Kuhn, J., D. Lenartz, W. Huff, S. Lee, A. Koulousakis, J. Klosterkoetter, and V. Sturm. 2007. Remission of alcohol dependency following deep brain stimulation of the nucleus accumbens: Valuable therapeutic implications? Journal of Neurology, Neurosurgery and Psychiatry 78: 1152-1153.

13. Franzini, A., C. Marras, P. Ferroli, O. Bugiani, and G. Broggi. 2005. Stimulation of the posterior hypothalamus for medically intractable impulsive and violent behavior. Stereotactic and Functional Neurosurgery 83: 63-66.

14. Greely, H.T. 2008. Neuroscience and criminal justice: Not responsibility but treatment. Kansas Law Review 56: 11031138.

15. Goethals, I., F. Jacobs, C. Van der Linden, J. Caemaert, and K. Audenaert. 2008. Brain activation associated with deep brain stimulation causing dissociation in a patient with Tourette's Syndrome. Journal of Trauma \& Dissociation 9 (4): 543-549.

16. U.S. National Institutes of Health. 2008. Deep Brain Stimulation (DBS) for Alzheimer's Disease (NCT00658125). http://clinicaltrials.gov/ct2/show/NCT00658125?term= alzheimer+dbs\&rank=1. Accessed October 2009.

17. Morrison, C.E., J.C. Borod, K. Perrine, A. Beric, M.F. Brin, A. Rezai, P. Kelly, D. Sterio, I. Germano, D. Weisz, and C.W. Olanow. 2004. Neuropsychological functioning following bilateral subthalamic nucleus stimulation in Parkinson's disease. Archives of Clinical Neuropsychology 19(2): 165-181.

18. Trépanier, L.L., R. Kumar, A.M. Lozano, A.E. Lang, and J. A. Saint-Cyr. 2000. Neuropsychological outcome of GPi pallidotomy and GPi or STN deep brain stimulation in Parkinson's disease. Brain and Cognition 42(3): 324-347.

19. Voon, V., C. Kubu, P. Krack, J.-L. Houeto, and A.I. Tröster. 2006. Deep brain stimulation: Neuropsychological and neuropsychiatric issues. Movement Disorders 21(14): 305-326.

20. Voon, V., P. Krack, A.E. Lang, A.M. Lozano, K. Dujardin, M. Schupbach, J. D'Ambrosia, S. Thobois, F. Tamma, J. Herzog, J.D. Speelman, J. Samanta, C. Kubu, H. Rossignol, Y.-Y. Poon, J.A. Saint-Cyr, C. Ardouin, and E. Moro. 2008. A multicentre study on suicide outcomes following subthalamic stimulation for Parkinson's disease. Brain 131: 2720-2728.

21. Burkhard, P.R., F.J.G. Vingerhoets, A. Berney, J. Bogousslavsky, J.-G. Villemure, and J. Ghika. 2004. Suicide after successful deep brain stimulation for movement disorders. Neurology 63: 2170-2172.

22. Soulas, T., J.-M. Gurruchaga, S. Palfi, P. Cesaro, J.-P. Nguyen, and G. Fenelon. 2008. Attempted and completed suicides after subthalamic nucleus stimulation for Parkinson's disease. Journal of Neurology, Neurosurgery and Psychiatry 79: 952-954.

23. Leentjens, A.F.G., V. Visser-Vandewalle, Y. Temel, and F.R.J. Verhey. 2004. Manipuleerbare wilsbekwaamheid: een ethisch probleem bij elektrostimulatie van de nucleaus subthalamicus voor ernstige ziekte van Parkinson. Nederlands Tijdschrift voor Geneeskunde 148: 1394-1397.

24. Mandat, T.S., T. Hurwitz, and C.R. Honey. 2006. Hypomania as an adverse effect of subthalamic nucleus stimulation: Report of two cases. Acta Neurochirurgica (Wien) 148: 895-898.

25. Chamorro-Premuzic, T. 2007. Personality and individual differences. Oxford: Blackwell.

26. Epstein, S. 1979. The stability of behavior: I. On predicting most of the people much of the time. Journal of Personality and Social Psychology 37(7): 1097-1126.

27. Ryckman, R.M. 2008. Theories of personality. Belmont, CA: Wadsworth/Thomson Learning.

28. Castelli, L., P. Perozzo, M. Caglio, L. Rizzi, M. Zibetti, M. Lanotte, and L. Lopiano. 2008. Does subthalamic stimulation induce personality modifications in Parkinson's disease? A Rorschach Test explorative study. Acta Neurologica Belgica 108: 5-8.

29. Decker, M., and T. Fleischer. 2008. Contacting the brainaspects of a technology assessment of neural implants. Biotechnology Journal 3: 1502-1510.

30. Kopell, B.H., and B.D. Greenberg. 2008. Anatomy and physiology of the basal ganglia: Implications for DBS in psychiatry. Neuroscience and Biobehavioral Reviews 32: 408-422.

31. Hariz, M.I., S. Rehncrona, N.P. Quinn, J.D. Speelman, C. Wensing, and the Multicentre Advanced Parkinson's Disease Deep Brain Stimulation Group. 2008. Multicenter study on deep brain stimulation in Parkinson's disease: An independent assessment of reported adverse events at 4 years. Movement Disorders 23: 416-421.

32. Ministerie van Justitie. 2007. Handreiking voor de beoordeling van wilsbekwaamheid. http://www.justitie.nl/images/ Handreiking $\% 20$ beoordeling\%20wilsonbekwaamheid $\%$ 20dec2006_tcm34-34470.pdf. Accessed March 2010.

33. Butler, J. 1736. Of Personal Identity. In The Analogy of Religion, reprinted in Perry 1975/2008, 99-105; page references are to the reprinted version.

34. DeGrazia, D. 2005. Human identity and bioethics. Cambridge: Cambridge University Press.

35. Locke, J. 1694/1975. An essay concerning human understanding. Oxford: Oxford University Press.

36. MacIntyre, A. 1984. After virtue. Notre Dame: University of Notre Dame Press.

37. Parfit, D. 1971. Personal identity. The Philosophical Review 80: 3-27.

38. Parfit, D. 1984. Reasons and persons. Oxford: Oxford University Press.

39. Perry, J. 1975/2008. Personal identity, 2nd ed. Berkeley: University of California Press.

40. Reid, T. 1785. Of Memory. In Essays on the Intellectual Powers of Man, reprinted in Perry 1975/2008 as "Of Identity" (pp. 107-112) and "Of Mr. Locke's Account of Our Personal Identity" (pp. 113-118); page references are to the reprinted version. 
41. Olson, E.T. 1997. Was I ever a fetus? Philosophy and Phenomenological Research 58: 95-109.

42. Shoemaker, S. 1970. Persons and their pasts. American Philosophical Quarterly 7: 269-285.

43. Shoemaker, S. 1996. The first-person perspective and other essays. Cambridge: Cambridge University Press.

44. Shoemaker, D. 2008. Personal Identity and Ethics. The Stanford Encyclopedia of Philosophy. http://plato.stanford. edu/archives/fall2008/entries/identity-ethics/. Accessed March 2010.

45. Slors, M. 2001. The diachronic mind: An essay on personal identity, psychological continuity and the mind-body problem. Berlin: Springer.

46. Unger, P. 1990. Identity, consciousness, and value. New York: Oxford University Press.

47. Patrick, C.J., J.J. Curtin, and A. Tellegen. 2002. Development and validation of a brief form of the multidimensional personality questionnaire. Psychological Assessment 14(2): $150-163$.

48. Donellan, M.B., R.D. Conger, and B. Burzette. 2005. Criterion-related validity, self-other agreement, and longitudinal analyses for the Iowa personality questionnaire: A short alternative to the MPQ. Journal of Research in Personality 39: 458-485.

49. Witt, K., C. Daniels, J. Reiff, P. Krack, J. Volkmann, M.O. Pinsker, M. Krause, V. Tronnier, M. Kloss, A. Schnitzler, L. Wojtecki, K. Botzel, A. Danek, R. Hilker, V. Sturm, A. Kupsch, E. Karner, and G. Deuschl. 2008. Neuropsychological and psychiatric changes after deep brain stimulation for Parkinson's disease: A randomized, multicentre study. Lancet Neurology 7(7): 605-614.

50. Sensi, M., R. Eleopra, M.A. Cavallo, E. Sette, P. Milani, R. Quatrale, J.G. Capone, V. Tugnoli, M.R. Tola, E. Granieri, and P.G. Data. 2004. Explosive-aggressive behavior related to bilateral subthalamic stimulation. Parkinsonisim and Related Disorders 10: 247-251.

51. Herzog, J., J. Reiff, P. Krack, K. Witt, B. Schrader, D. Müller, and G. Deuschl. 2003. Manic episode with psychotic symptoms induced by subthalamic nucleus stimulation in a patient with Parkinson's disease. Movement Disorders 18(11): 1382-1384.

52. Morse, S.J. 2006. Moral and legal responsibility and the new neuroscience. In Neuroethics: Defining the issues in theory, practice, and policy, ed. J. Iles, 33-50. Oxford: Oxford University Press.

53. Article 39, Criminal Code Netherlands. http://wetten.overheid. nl/BWBR0001854/EersteBoek/TitelIII/Artikel39/geldigheids datum 29-03-2010. Accessed February 2010.

54. Frank, M.J., J. Samanta, A.A. Moustafa, and S.J. Sherman. 2007. Hold your horses: impulsivity, Deep Brain Stimulation, and medication in Parkinsonism. Science 318: 13091312 .

55. McNally, R.J., S.A. Clancy, D.L. Schacter, and R.K. Pitman. 2000. Personality profiles, dissociation, and absorption in women reporting repressed, recovered, or continuous memories of childhood sexual abuse. Journal of Consulting and Clinical Psychology 68: 1033-1037.

56. Merckelbach, H., and P. Muris. 2001. The causal link between self-reported trauma and dissociation: A critical review. Behaviour Research and Therapy 39: 245-254.
57. Pezzella, F.R., C. Colosimo, N. Vanacore, S. Di Rezze, M. Chianese, G. Fabbrini, and G. Meco. 2005. Prevalence and clinical features of hedonistic homeostatic dysregulation in Parkinson's disease. Movement Disorders 20(1): 77-81.

58. American Psychiatric Association. 1994. Diagnostic and statistical manual of mental disorders, 4th ed. Washington, DC: American Psychiatric Association.

59. Breggin, P.R. 2003/2004. Suicidality, violence and mania caused by selective serotonin reuptake inhibitors (SSRIs): a review and analysis. International Journal of Risk \& Safety in Medicine 16: 31-49.

60. Healy, D., A. Herxheimer, and D.B. Menkes. 2007. Antidepressants and violence: Problems at the interface of medicine and law. International Journal of Risk \& Safety in Medicine 19: 17-33.

61. Kaufman, J.M. 2009. Selective serotonin reuptake inhibitor (SSRI) drugs: More risks than benefits? Journal of American Physicians and Surgeons 14(1): 7-12.

62. Dorevitch, A., Y. Frankel, A. Bar-Halperin, R. Aronzon, and L. Zilberman. 1993. Fluvoxamine-associated manic behavior: A case series. The Annals of Pharmacotherapy 27(12): 1455-1457.

63. Okado, F., and K. Okajima. 2001. Violent acts associated with fluvoxamine treatment. Journal of Psychiatry \& Neuroscience 26: 339-340.

64. Merckelbach, H., M. Jelicic, C. de Ruijter. 2009. De B. heeft een persoonlijkheidsstoornis en doodt zijn vriendin. Maandblad Geestelijke Volksgezondheid 9: 747-759.

65. Haque, Q., and I. Cumming. 2003. Intoxication and legal defences. Advances in Psychiatric Treatment 9: 144-151.

66. Court Arnhem. LJN AS9894. 2005.

67. Court Haarlem. LJN BK4178. 2009.

68. Kennett, J., and S. Matthews. 2002. Identity, control and responsibility: The case of dissociative identity disorder. Philosophical Psychology 15(4): 509-526.

69. Braude, S.E. 1996. Multiple personality and moral responsibility. Philosophy, Psychiatry and Psychology 3: 37-54.

70. Saks, E.R. 1995. The criminal responsibility of people with multiple personality disorder. The Psychiatric Quarterly 66: 119-131.

71. Thigpen, C.H., and H. Cleckley. 1954. A case of multiple personality. Journal of Abnormal and Social Psychology 49: $135-51$.

72. Sinnott-Armstrong, W., and S. Behnke. 2000. Noûs, Vol. 34, Supplement: Philosophical Perspectives, Action and Freedom 14: 301-323.

73. Stevens, L., and M.M. Prinsen. 2009. Afwezigheid van opzet bij de geestelijk gestoorde verdachte. Het gedragskundig oordeel vanuit juridisch perspectief. Expertise en Recht 5(6): 113-119.

74. Court Assen. LJN AE3911. 2002.

75. Bell, E., G. Mathieu, and E. Racine. 2009. Preparing the ethical future of deep brain stimulation. Surgical Neurology 72: 577-586.

76. Rabins, P., B.S. Appleby, J. Brandt, M.R. DeLong, L.B. Dunn, L. Gabriels, B.D. Greenberg, S.N. Haber, P.E. Holtzheimer, Z. Mari, H.S. Mayberg, E. McCann, S.P. Mink, S. Rasmussen, T.E. Schlaepfer, D.E. Vawter, J.L. Vitek, J. Walkup, and D.J.H. Mathews. 2009. Scientific and ethical issues related to deep brain stimulation for disorders 
of mood, behavior, and thought. Archives of General Psychiatry 66(9): 931-937.

77. Glannon, W. 2008. Stimulating brains, altering minds. Journal of Medical Ethics 35: 289-292.

78. Berghmans, R.L.P., and G.M.W.R. de Wert. 2004. Mental competence in the context of deep brain stimulation. Nederlands Tijdschrift voor Geneeskunde 148: 1373-1375.

79. Wet Bijzondere Opname in Psychiatrische Ziekenhuizen (Law on Special Admission to Psychiatric Hospitals). http://wetten. overheid.nl/BWBR0005700/geldigheidsdatum_18-11-2009. Accessed February 2010. 